\title{
MIGRACIÓN, INTEGRACIÓN Y NACIONALISMO: REFLEXIONES PARA UNA CIUDADANÍA INCLUSIVA ${ }^{1}$
}

\section{MIGRATION, INTEGRATION AND NATIONALISM: REFLECTIONS FOR AN INCLUSIVE CITIZENSHIP}

Menara Lube Guizardi*

Resumen: El presente texto reflexiona sobre el concepto de integración social, vinculándolo a los debates sobre ciudadanía en el marco de Estados democráticos. Para esto, discutiremos cómo la ideología de homogeneidad constitutiva en los Estados nacionales modernos ha impregnado el concepto de ciudadaní, condicionando una relación intrínseca entre éste y los principios de libertad e igualdad. Ejemplificaremos cómo los mecanismos de concesión de la Tarjeta de Residencia y de nacionalización de migrantes en España construyen fronteras nacionales que reinciden en estas concepciones modernas de exclusión/inclusión a la nación. En las conclusiones, apuntamos hacia un concepto de participación ciudadana respaldado en la noción de consenso dialógico.

Palabras clave: Integración, democracia, migración, ciudadanía, consenso dialógico.

Abstract: This paper discusses the concept of social integration, linking it to the debates on citizenship in the context of democratic

Universidad Alberto Hurtado (Chile).

1 Este artículo se desarrolla en el marco del Proyecto I+D «Conflictividad y migración en contextos locales. Una aproximación teórico-práctica a la convivencia y la mediación» del Instituto de las Migraciones, Etnicidad y Desarrollo Social (Universidad Autónoma de Madrid), dirigido por Carlos Giménez. 
states. The discussion sheds light upon how the ideology of constitutive homogeneity in modern Nation-States has imbued the concept of citizenship, debating the intrinsic relationship of this concept to the principles of freedom and equality. The text also exemplifies how the mechanisms for granting the residence card and nationalization of migrants in Spain build national borders, relapsing into modern conceptions of exclusion / inclusion. In the conclusions, a concept of citizen participation based on dialogic consensus is proposed.

Keywords: Integration, democracy, migration, citizenship, dialogic consensus.

\section{INTRODUCCIÓN}

«El inmigrante arrastra consigo el estigma de haber nacido mal, a destiempo, en el lado malo de la geografía. Por eso lo que nunca se plantea es la verdadera integración, la que corresponde a quien no vive entre nosotros provisionalmente, parcialmente, sino a quien quiere ser uno de los nuestros, sólo que de un nosotros plural». (De Lucas, 2001:67).

El presente texto discute el concepto de integración social, vinculándolo a los debates sobre la ciudadanía, en el marco de los Estados multinacionales y poliétnicos como España en la actualidad (Kymlicka, 1995:13-15)2. El concepto de ciudadanía estuvo históricamente apoyado en concepciones geográficas y políticas que evocan la identidad nacional, soberanía y control estatal (Benhabib, 2004:13): relaciones que vienen siendo activamente desafiadas por la magnitud y diversidad de la migración internacional (Bloemraad et al 2008:153). En el contexto de esta discusión debatiremos la importancia de los mecanismos sociales de participación para el mantenimiento del diálogo democrático. Para generar una democracia dinámica, capaz de asumir los conflictos que devienen de la diversidad de perspectivas y de los procesos de expresión pública de las diferencias (Mouffe,

2 Para Kymlicka (1995:18), los Estados multiculturales pueden ser clasificados como multinacionales — cuyos miembros pertenecen a diferentes naciones internas- y poliétnicos — diversificados por la recepción de inmigrantes provenientes de otros países, pueblos, o etnias. 
1999), es necesario considerar como central las distintas formas de participación ciudadana y los canales que permiten su potenciación.

Estos temas han ocupado un espacio considerable en la agenda pública española de las últimas décadas, principalmente por el aumento significativo de la población migrante ${ }^{3}$. Sin embargo, es un error comprender este debate sólo en vinculación a un fenómeno «provocado por» o «restringido a» la migración. La cuestión de la integración entre personas o grupos diferentes va más allá de la casuística migratoria. Ella tiene, en efecto, una relación intrínseca con la diversidad constitutiva del Estado español y con la dificultad de generar procesos sociales de diálogo que permitan que esta diversidad conviva activamente en el marco de las instituciones democráticas.

La institucionalización de la democracia en España encierra cierta ambivalencia respeto a la convivencia e integración, dejando margen a dudas sobre cómo entender legalmente estos dos principios de sociabilidad. En su preámbulo, la Constitución Española (CE) proclama la voluntad de la nación de «establecer la justicia, la libertad y la seguridad y promover el bien de cuantos la integran" (CE, 1978). En la descripción de los objetivos que alcanzar para promover la justicia, libertad y seguridad, se establece como primera meta: "garantizar la convivencia democrática dentro de la constitución y de las leyes conforme a un orden económico y social justo». La problemática surge debido a que estos «cuantos que la integran» se definen categóricamente a partir del principio de nacionalidad dado por el jus soli y por el jus sanguinis ${ }^{4}$.

3 Esta es una realidad que ha cambiado a raíz de la crisis económica. Desde 1994 hasta 2009, España presentó un número de inmigrantes superior al número de emigrantes. Sin embargo, a partir de 2010, el país presenta stock migratorio negativo, observándose la emigración de españoles y retorno a países de origen de los migrantes. Para informaciones sobre los contingentes migratorios internacionales en España, véase (INE, 1996-2011).

4 «Se distingue, por tanto, entre atribución de la nacionalidad española por el hecho del nacimiento (a lo que ha de añadirse los supuestos de menores de edad adoptados por españoles a tenor de lo preceptuado en el art. 19 del Código Civil (Cc), y adquisición de modo derivativo, por opción, carta de naturaleza o residencia en España, nacionales españoles que podrán verse privados de su nacionalidad cuando se produzcan alguno de los supuestos contemplados en el art. 25 del Cc. (...) La naturalización supone una concesión por parte del Estado para la cual es requisito indispensable el juramento o promesa de fidelidad al Rey y obediencia a la Constitución y Leyes, requisitos que también han de ser cumplidos cuando se adquiere la nacionalidad española por opción» (Rubio y Moya (2003:108). 
Lo paradójico es que el sistema jurídico español entiende la igualdad como trato equivalente entre los iguales y desigual entre los que no gozan del vínculo de pertenencia, que en la Constitución está dado por el principio de nacionalidad. La Constitución proclama la centralidad de la integración y de la convivencia en el marco de la democracia, pero deja abierto el problema de cómo incluir a los nuevos habitantes de la nación en este cómputo. En gran medida, el marco normativo constitucional se ha convertido en anacrónico en estos tiempos de globalización de los flujos humanos, en los que la migración se ha intensificado. Se genera así la necesidad de incidir en un debate público acerca de la redefinición del sentido de pertenencia —extendiendo la categorización de aquellos que tendrán derecho a ser «tratados cómo iguales»- para hacer surgir nuevas formas de ciudadanía que contemplen otras vinculaciones (Benhabib, 2004:15), quizás más acordes a la noción de jus domicili (Castle y Davidson, 2000), pensada desde la experiencia de pertenecer y participar de la ciudadanía desde espacios locales (Kazama, 2011).

Simultáneamente, la indefinición normativa de las nociones de convivencia e integración en términos jurídicos ha dado paso a que, más allá de los valores proclamados constitucionalmente, se establezcan prácticas sociales selectivas por parte del Estado y de la población. Y son justamente estas prácticas — que se moldean de acuerdo al matiz político de los tiempos y a la inestabilidad de las circunstanciaslas que definen cotidianamente quienes pueden integrarse y convivir, y quienes no. Entonces, pese a que la integración y la convivencia se proclaman como valores fundacionales de la democracia, la práctica cotidiana de las instituciones designa selectivamente a los beneficiarios de estos valores, impugnando la calidad de universal asociada a la expresión «cuantos la integran». En estricto sentido, si la democracia depende de integrar y convivir, y si sólo es efectiva para quienes pertenecen a determinado grupo, entonces hablamos de una democracia selectiva y socialmente ubicada. Una democracia excluyente.

El debate que proponemos en este artículo busca aportar a la comprensión de la frase constitutiva «todos los que la integran». Pensamos que esta debe ser definida sobre la base de la participación en diferentes esferas sociales, lo que implica trasladarnos de una noción de pertenencia e igualdad fundada en la nacionalidad hacia una de ciudadanía plural. Para la consecución de los objetivos de este trabajo se aborda, primeramente, una noción inicial de ciudadanía, la que iremos complejizando en las secciones siguientes. Posteriormente, 
debatimos cómo la ideología de una homogeneidad racial en los Estados nacionales modernos ha impactado el concepto de ciudadanía, discutiendo su relación intrínseca con los principios de libertad e igualdad y, al mismo tiempo, redefiniendo el concepto de integración social. Asimismo, abordamos cómo los mecanismos de concesión de la Tarjeta de Residencia y de nacionalización de migrantes en España construyen fronteras nacionales que reinciden en concepciones modernas de exclusión/inclusión a la nación. En definitiva, aventurando las conclusiones, apuntamos hacia un concepto de participación ciudadana respaldado en activación del consenso dialógico.

\section{CIUDADANÍA: REFERENCIAS Y SIGNIFICADOS}

Antes de profundizar en la discusión sobre integración social, en sociedades receptoras de migración, conviene explicitar brevemente algunos de los significados históricamente atribuidos a la noción de ciudadanía en contextos democráticos. El principal problema, en este sentido, resulta de la imposibilidad de hablar unánimemente del concepto de ciudadanía y/o de ciudadanas(os). La existencia y el uso político de la palabra determinan que su sintaxis varíe de acuerdo a los significados que le asignen el Estado, la esfera pública y la sociedad civil. Zapata-Barrero (2001:7) se refiere a concepciones y no a conceptos de ciudadanía, asumiendo el término como fundamentalmente polisémico. Apoyándonos en la reflexión de este autor, destacamos cinco dimensiones relacionales que la constituyen como fenómeno político de la vida social:

1) La ciudadanía es la posición que la persona alcanza por «adscripción o consecución con el consentimiento y el respaldo del Estado para actuar en la esfera pública» (Zapata-Barrero, 2001:7). Pensada la noción, estrictamente, desde esta dimensión jurídica, ella puede ser entendida estáticamente. Es decir, uno tiene o no la ciudadanía.

2) La ciudadanía implica supuestamente, desde el punto de vista de la acción social, una práctica constante de participación (Bauböck, 1994: 296). Debe ser tomada, entonces, como la acción de participar como "persona pública» de la construcción diaria del Estado, lo que implica una relación dinámica entre lo social y lo político (Zapata-Barrero, 2001:7). 
3) El ciudadano también es la percepción estatal de la persona, pudiendo la ciudadanía ser pensada como una relación vertical entre el Estado y la gente.

4) Para ser ciudadano se debe estar situado en la esfera pública. Los y las ciudadanos(as) deben transformar en acción social aquello que en potencia es un derecho adquirido frente a las instituciones estatales. Por lo tanto, puede que el espacio ocupado por uno en el ejercicio de la ciudadanía determine el matiz con que su pertenencia sea interpretada tanto por el Estado como por los demás ciudadanos. Esto hace referencia al concepto de participación bidireccional de Aristóteles: el ciudadano como aquél que obedece a las reglas civiles y que simultáneamente las elabora; el que gobierna y es gobernado.

5) Finalmente, es conveniente retomar la perspectiva de De Lucas (2001:68) quien reincide en las reflexiones de Marshall (1992:2223), considerando que la ciudadanía democrática involucra tres categorías de derechos. 1) Las libertades negativas, comprendidas como la seguridad jurídica del ciudadano. 2) Los derechos sociales, expresamente manifiestos en el acceso a las instituciones de lo que se consideró en su momento el «Estado de bienestar social». 3) Los derechos políticos, comprendidos como la posibilidad de manifestación política de la opinión, demanda y diversidad (particular de cada individuo o de los grupos de individuos). Es usual que este derecho se confunda con el simple acceso a los mecanismos representativos. A estas tres dimensiones jurídicas del concepto de ciudadanía, Bloemraad et al (2008:154) añadirían una cuarta, de carácter sociológico, si se quiere: el sentido de pertenencia.

\section{REPLANTEAR LA INTEGRACIÓN: LIBERTAD, IGUALDAD Y LAS MITOLOGÍAS DE LA HOMOGENEIDAD NACIONAL}

El mito de la homogeneidad nacional interna dejó marcas muy fuertes en la totalidad de los Estados-nación europeos, cuya centralización — a partir de fines del siglo XVIII— obligó a la supresión de las diferencias culturales internas (Hobsbawn, 1997:114), forjando la ideología de que la unidad de la nación sobre un territorio (circunscrito por unas fronteras euclidianas) era homóloga a la unidad lingüística, étnica, racial, religiosa, artística, social y política (Hastings, 
2000:14; Bloemraad et al, 2008:154). Esta ideología de la unidad dio origen a numerosos mecanismos de violencia en contra de la pluralidad interna (Appadurai, 2006:3; Hastings, 2000:18). La invención de la nación, como la estructura básica del sentido de pertenencia de un pueblo, obligó a la creación de íconos nacionales (banderas, himnos, héroes, mitos fundacionales) que tenían la finalidad de sustituir los objetos de adoración religiosa (Zapata-Barrero, 2001:36). Este proceso da paso a la invención de las tradiciones (Hobsbawn y Ranger, 1984) que permitirían dibujar una memoria pública (Fabian, 2007) sobre la ontología de la nación, confirmando en ella la yuxtaposición entre pueblos, fronteras y lenguas nacionales ${ }^{5}$.

Dos ideologías de pertenencia nacional (y de vinculación ciudadana) se definieron a partir de la unificación de los Estados-nacionales europeos (Brubaker, 1992). En primer lugar, la noción francesa de jus solis, según la que todos aquellos y aquellas que nacen en el territorio limitado por el Estado son ciudadanos/as (Kazama, 2011:2). En este modelo se genera el Estado unificado y, posteriormente, se forja en el plano político-social (gracias a los Aparatos Represivos e Ideológicos del Estado ${ }^{6}$ ) la unidad cultural del pueblo. En segundo lugar, surge el modelo alemán del jus sanguinis, el que se fundamenta en la idea del surgimiento de una lengua y culturas hegemónicas que están determinadas por la supuesta homogeneidad biológica de aquéllos que las poseen. Esta cultura consanguínea se asume como la justificación del surgimiento del Estado uno. Aquí, la unidad del Estado se ampara en la ideología de la unidad sanguínea de quienes comparten la misma cultura (Hastings, 2000:26; Zapata-Barrero, 2001:37).

5 Las naciones en general se han constituido históricamente como comunidades inventadas (Anderson, 2007), con un activo proceso de invención de tradiciones (Hobsbawn y Ranger, 1984) que muy a menudo han conllevado discriminación - operada a partir de violencia simbólica, y también a partir de la guerra contra los otros externos e internos de la nación (Brubaker, 1992).

6 Concordamos con Althusser (1969, s/p) para quien los aparatos del Estado (AE) comprenden: «el gobierno, la administración, el ejército, la policía, los tribunales, las prisiones, etc., que constituyen lo que llamaremos desde ahora el aparato represivo de Estado. Represivo significa que el aparato de Estado en cuestión "funciona mediante la violencia", por lo menos en situaciones límite (pues la represión administrativa, por ejemplo, puede revestir formas no físicas). Designamos con el nombre de aparatos ideológicos de Estado cierto número de realidades que se presentan al observador inmediato bajo la forma de instituciones distintas y especializadas». 
La tarea de construir la unicidad de los miembros de la nación implicó la consideración de una dimensión biológica (Foucault, 2007) de la pertenencia nacional, tanto en el jus solis como en el jus sanguinis. El pueblo nacional pertenecería a una misma raza de hombres que se distingue de las otras existentes en territorios más allá de las fronteras. La identidad nacional se yuxtapuso, desde muy tempranamente en su desarrollo (entre los siglos XVIII y XIX), a la idea de una biología común. La ciudadanía, como manifestación directa de la nacionalidad, se impregnó de esa moralidad racista.

Entre los años 1870 y 1914, los mitos de homogeneidad racial se naturalizan entre los Estados europeos, amalgamando una idea de ciudadanía prácticamente equivalente a una concepción de raza y de nacionalidad (Hobsbawn, 1997:117). Ese proceso de inscripción biológica de la especificidad nacional de las poblaciones forma parte de lo que Michel Foucault denomina bio-política del poder (Foucault, 2006). Para el filósofo francés, la capacidad de gobernar a los seres humanos surge en la modernidad europea de manera yuxtapuesta al descubrimiento de la capacidad productiva de sus cuerpos. El control de los cuerpos se transforma así en objeto sine qua non de los sistemas políticos. Con el surgimiento del capitalismo, se instaura como modelo hegemónico de dominación de los cuerpos su inscripción en regímenes disciplinarios basados en la vigilancia y el castigo, generando corporalidades dóciles y productivas (Foucault, 2004). La homogenización de la población nacional, bajo la pretendida unidad de una raza común, está fuertemente vinculada al control corporal de los ciudadanos en tanto forma viva prioritaria del proyecto de centralización política nacional:

«(...) Situar el racismo desde el Estado, no sólo como una ideología de la diferencia y de la desigualdad; no sólo como forma de dominación y opresión entre grupos étnicos, sino como una lógica de exterminio y de la exclusión, como una tecnología del poder». (Casaús-Arzú, 2006:11).

Así, la historicidad del nacionalismo y del racismo supone problemas de poder, ideología y política que no se pueden entender únicamente como factores de orden cultural (Hobsbawn, 1997:120). Las reacciones xenófobas y racistas, presentes en la vida cotidiana, tienen relación con el miedo hacia una pluralidad social que desestabilice la unidad nacional-ciudadana históricamente construida. Un temor se manifiesta muy a menudo en el rechazo incesante a la incorporación de 
los «otros» a los derechos de la ciudadanía de los «unos» (Hobsbawn, 1997:180). Ese último aspecto corresponde a lo que Mouffe llama la «recreación de una frontera política» mediante la invención de un «nuevo enemigo» (1999:17), lo que está políticamente mediado por el concepto de ciudadanía como frontera conceptual, legal e ideológica de inclusión/exclusión de la nación (Kazama, 2011:2; Brubaker, 1992: 2).

Debemos considerar, entonces, que el renacimiento de un racismo (que se daba por extinguido) en las democracias europeas actuales guarda una intensa conexión con los sentimientos públicos de pertenencia a las naciones, y de garantía de los derechos que se creen un privilegio de aquéllos que se consideran ciudadanos. El racismo resurge con toda su fuerza en los actuales contextos receptores de migración (Bloemraad et al, 2008:161) gracias a que la noción de ciudadanía sigue implicando un sentimiento público que la racializa. Aunque el racismo no se permite en los niveles discursivos estatales, su lógica aún opera en los sentimientos, ideas y acciones públicas de la gente, constituyendo una especie de memoria colectiva de los sentidos de pertenencia nacional. Esta memoria pública circula de la esfera privada a la pública y viceversa, desdibujando la frontera entre la una y la otra.

Consecuentemente, el debate sobre la integración entre diferentes es una problemática relevante desde la formación del Estado-Nación y debe ser comprendida como vinculada a la producción de los procesos mitológicos de «otredad», propios del nacionalismo moderno. Se dibuja un imaginario nacional sobre los «otros» y su barbarie y sobre la necesidad de evitar que la visión de mundo de estos otros «contamine» la sociedad «autóctona» (Benhabib, 2004; Brubaker, 1992). Esta frontera de otredad se construye sobre una serie de mitologías de la diferencia, basadas en movimientos de inclusión y exclusión que dialogan activamente con las definiciones identitarias nacionales (Brubaker, 1992; Bauböck, 1994; Kazama, 2011)7. En tiempos de crisis económica, como los que se viven actualmente en España, la desarticulación del Estado de Bienestar Social y el empobrecimiento

7 La contradicción inclusión/exclusión sería inherente a todo proceso identitario, y no solamente a las identidades nacionales: «el rasgo estructural que se supone que todas las identidades comparten es una incompletud constitutiva. (...) La "incompletud" de todas y cada una de la identidades es el resultado directo de su emergencia diferencial: ninguna identidad particular puede emerger sin suponer y establecer exclusión de otras, y esta exclusión constitutiva o antagonismo es la condición compartida por toda constitución identitaria» (Butler, 2011:39). 
de la población — reflejado en los índices de desempleo del 27,16\% y en el crecimiento al $21,8 \%$ de población por debajo el umbral de la pobreza (INE, 2011) — han contribuido a una atmósfera de inestabilidad que, además de económica, es también moral, social y política.

Este fenómeno conlleva la pérdida general de referencias sociales comunes, abriendo paso al regreso de sentimientos colectivos que permiten recrear la ficción de "unidad social estable». En este momento, el nacionalismo reaparece con una tónica social sorprendente, retomando de la modernidad europea su «objeto de identificación y adhesión voluntarias favorito: la unidad nacional» (Gellner, 2001:78), la que trae consigo la xenofobia y el racismo como demarcadores colectivos de las fronteras nacionales:

"A los "otros" se puede, se debe culpar de todos los agravios, incertidumbres y desorientaciones que sentimos tantos de "nosotros" (...) ¿Y quiénes son los "otros"? Obviamente, y virtualmente por definición, los que no son los "unos", los extraños que son enemigos por su propia condición de extraños. (...) Nuestra propia coexistencia con los "otros" mina ahora las certezas exclusivas de pertenecer a nuestro propio pueblo, a nuestra propia nación». (Hobsbawn, 1997:184).

El sentimiento de exclusión de los «otros» pasa a cumplir un papel de cohesión social entre los «unos», pues el nacionalismo es un «sustituto de factores de integración en una sociedad que se está desintegrando. Cuando la sociedad fracasa, la nación reaparece como garantía última» (Hroch en Hobsbawn, 1997:183). Esta múltiple desestabilización de los valores de identificación social colectiva, acompañada del rebrote del deseo de exclusión de los «diferentes», es fundamental para explicar por qué la migración se convirtió en uno de los elementos sociales que materializan el descontento de la población española en el contexto de crisis. El debate sobre la ciudadanía es clave para relativizar tanto este sentido de exclusión del «otro», como su relación con la ideología de homogeneidad nacional constitutiva. En este debate, el concepto de integración asume un papel central, pues «la transformación del modelo excluyente y monista de ciudadanía en uno plural e inclusivo pasa por una redefinición del proceso de integración y del vínculo de ciudadanía»(De Lucas, 2001: 53).

8 Datos del INE para mayo de 2013. Véase: http://www.ine.es/ 
Para definir integración social adoptamos como punto de partida la noción propuesta por Giménez, quien la define como:

«(...) generación de cohesión social y convivencia intercultural, mediante procesos de adaptación mutua entre sujetos jurídica y culturalmente diferenciados, mediante los cuales a) las personas de origen extranjero se incorporan en igualdad de derechos, obligaciones y oportunidades a la población autóctona, sin por ello perder su identidad y cultura propias; b) la sociedad y el Estado receptor introducen paulatinamente aquellos cambios normativos, organizativos, presupuestarios y de mentalidad que se hagan necesarios» (Giménez, 1993).

En esta definición encontramos un cruce entre libertad e igual$\mathrm{dad}$, dos valores fundamentales para la articulación política de las democracias, los que, sin embargo, han sido asumidos como ontológicamente contradictorios, o de muy difícil conciliación por buena parte del pensamiento político contemporáneo. La paradoja de la conciliación entre libertad e igualdad (Marshall, 1992:22) puede ser definida en términos sencillos mediante la sentencia: si todos somos iguales, entonces no podemos ser libres para ser diferentes y si todos somos libremente diferentes, ¿cómo podemos ser iguales?? Según Giménez, el modelo de integración social implica que el sujeto debe incorporarse en igualdad de derechos, teniendo simultáneamente salvaguardado el derecho a la diferencia, pues no debe «perder su identidad y cultura propias». Es en este sentido que su

9 En relación al debate sobre la experiencia político-relacional de estos dos valores, en el marco de diferentes regímenes políticos, indicamos el clásico libro de Norberto Bobbio (1993), «Igualdad y Libertad». En este texto se analiza el uso de esos términos en la conformación de diferentes modelos estatales e ideologías desde la Revolución Francesa. Es interesante constatar que modelos políticos diametralmente opuestos han usado variablemente uno u otro de estos conceptos con resultados prácticos muy disonantes. Concordamos particularmente con la premisa de Bobbio en cuanto a que la igualdad sólo puede existir en el marco de relaciones sociales que estipulen su coherencia última: «(...) "X es igual” es una proposición sin sentido, antes bien remite, para adquirir sentido, a la respuesta a la pregunta “iigual a quién?”. De ahí el efecto irresistiblemente cómico, y en la intención del autor satírico, del célebre dicho orwelliano: "todos somos iguales, pero unos más iguales que otros"»(Bobbio, 1993:54). Discordamos del autor, sin embargo, en su asunción de que éste no sería el caso para el principio de libertad, ya que, según entendemos, la libertad depende de la construcción social relacional tanto o más intensamente que el principio de igualdad. 
propuesta presupone la conciliación de igualdad y libertad, desplazando él énfasis de la reflexión que, como decía Alfred Marshall, no debiera centrarse en indagar «si todos los hombres llegarán a ser iguales» (En T.H Marshall, 1998:18). Esta conciliación se resuelve en la argumentación de Giménez, porque ambos valores se asumen como restringidos a determinadas esferas de la vida social que no son necesariamente correspondientes, pese a que están en constante interacción, alterándose mutuamente. Por lo tanto, este autor no está hablando de la libertad e igualdad universalista de la Ilustración europea. La igualdad a la que se refiere existiría a niveles jurídicos, sociales y cívicos, mientras que la libertad lo haría como manifestación de la diferencia a niveles psicológicos y culturales — condiciones que presupondrían la aportación de la sociedad civil y de las instituciones del Estado, garantizando la experiencia social de las diferencias, y la institucionalización del derecho a igualdad en las esferas correspondientes ${ }^{10}$.

Esta proposición de un principio de libertad sedimentado en campos específicos de la vida social es bastante más compleja de lo que se puede apreciar a primera vista y significa una posición bastante interesante en relación a una encrucijada conceptual que, desde hace por lo menos dos siglos, viene provocando desacuerdos paradigmáticos en las ciencias sociales, influyendo centralmente en el concepto de ciudadanía ${ }^{11}$.

10 Este replanteamiento del principio de igualdad se hace imprescindible, además, debido a la conexión entre los derechos ciudadanos y la legitimación de la desigualdad de clase en los Estados-nacionales. La noción de ciudadanía en contextos democráticos ha surgido a partir de una generalizada aceptación de que la desigualdad de clase es justificable siempre y cuando se garanticen derechos formales de igualdad ciudadana, «hasta el punto que la ciudadanía se ha convertido, en ciertos aspectos, en el arquitecto de la desigualdad social legitimada» (Marshall, 1992:21-22). Esta relación perversa entre ciudadanía y reproducción social de la desigualdad se ha complejizado en contextos migratorios, en los que los migrantes se constituyen como una clase trabajadora que es doblemente desigual: primero, porque es frecuentemente explotada y situada en nichos informales y mal pagados; y, segundo, porque se encuentra impedida de asumir el nivel de igualdad formal (Milkman, 2011:368) que la ciudadanía presupuso históricamente en los Estado-nacionales.

11 Considérese que el concepto de libertad fue uno de los principales cimientos de la noción misma de ciudadanía en el proceso de construcción de los Estados-naciones en la modernidad europea, cuando «libertad y ciudadanía eran 
Históricamente, la cuestión de la libertad de los sujetos en el marco de la vida en sociedad ha sido discutida de acuerdo a diferentes cosmovisiones sociológicas. Por un lado, nos encontramos con la tradición de las ciencias sociales que, siguiendo a Durkheim en su ímpetu por delimitar la sociedad como un ente autónomo, sui generis y externo a los individuos, consideró la libertad como un oxímoron. Según este argumento, el poder determinador y normativo de la sociedad se entiende como cualitativamente (y estructuralmente) superior a la capacidad de autonomía del individuo, de manera que la propia condición de humanidad estaría supeditada por la adecuación al poder cohesionador de la sociedad (Durkheim, 1993). Por otro lado, en sentido diametralmente opuesto, estarían las teorías que conciben la capacidad de elección/transformación/ determinación de los individuos como superior a la de la sociedad. Estas teorías, cimiento ideológico de la economía liberal (y de sus derivados neo-liberales y utilitaristas), diagnostican que lo social no existe como orden autónomo, dado que la experiencia de la vida colectiva resulta de la libertad individual de autodeterminación (la supremacía del «individual choice»).

Más allá de la ausencia funcionalista de la libertad y de la reificación liberal de la libertad individual como motor de lo social, la propuesta de Giménez dialoga con un modelo de comprensión de la vida social en el que libertad y restricción son partes constituyentes del estar en sociedad. Este principio nos acerca a las consideraciones de Heidegger sobre cómo las interacciones sociales están basadas en un principio de libertad que es doblemente negativo y positivo (Evens, 2006). La libertad «negativa» estaría relacionada al reconocimiento y re-afirmación, por parte del sujeto, de los estándares socialmente establecidos; mientras la libertad "positiva» estaría asociada a la ruptura de las "prisiones socio-epistemológicas con la intención de proyectar las potencialidades» subjetivas (Evens, 2006:54). En ambos casos hay libertad, porque incluso cuando el sujeto se detiene en el cumplimiento de los estándares sociales, lo hace desde su propia posición subjetiva, desde un nivel mínimo de decisión ${ }^{12}$. Así, siempre habrá algún nivel de libertad de decisión en

términos intercambiables. Cuando la libertad se hizo universal, la ciudadanía pasó de institución local a nacional» (Marshall, 1992:29).

12 Esta relación entre sujeción y ruptura se activaría en la experiencia de las situaciones sociales cotidianas, en la relaciones de encuentro donde diferentes 
la vida social y esta peculiar libertad convive intrínsecamente con la objetivación de la sociedad y con la imposición de patrones, normas y valores externos a las personas ${ }^{13}$.

La cuestión fundamental no residiría en decidir hasta qué punto la libertad puede existir en un orden social estable, sino en definir qué contornos, límites y fronteras conformarían esta libertad para hacerla operacional, es decir, para enmarcarla normativamente dentro del Estado de derecho. Es en esa medida que la definición de la libertad en Giménez, como referente a campos específicos de la vida social, solventa la contradicción ontológica que el término presenta frente al concepto de igualdad cuando ambos son asumidos de manera universalista y totalizadora.

Consecuentemente, la propuesta de Giménez presupone que igualdad y libertad son conceptos políticamente determinados y que podrían ser modificados en las relaciones entre las personas y el Estado (y sus instituciones), alterándolas dinámicamente, a través de la retroalimentación entre el Estado y la sociedad civil. La integración

sujetos tienen que situacionalmente actualizar su adhesión a principios, normas, valores y a los diferentes subgrupos sociales a los que pertenecen y/o entre los cuales transitan. A respecto del papel de las situaciones sociales en la activación de este principio de libertad positiva y negativa, Evens (2006:59) afirmaba que «en la medida en que cualquier situación es determinada por sujetos interactuantes que retienen la capacidad de elección en alguna medida, las situaciones sociales permanecen siempre significantemente abiertas. Consecuentemente, toda y cada una de las situaciones es ética antes que política. Tomemos como ejemplo la nefasta situación de un campo de concentración, donde la capacidad de elección es tan limitada que la única real opción disponible puede ser entre una dura vida y ninguna vida. Aunque en un sentido profundo semejante elección no es elección en absoluto, en otro sentido ella marca la definición de la condición humana. Pues la patente inhumanidad de la elección marca la posibilidad de elección como tal — solamente los seres humanos tienen la elección de actuar de manera inhumana».

13 O, como expresa Bourdieu (2011:31): «Una de las preguntas fundamentales respecto del mundo social es la de saber por qué y cómo ese mundo dura, persevera en el ser, cómo se perpetúa el orden social, vale decir, el conjunto de relaciones de orden que lo constituyen. Para dar una respuesta veraz a esta pregunta, hay que rechazar tanto la visión "estructuralista", según la cual las estructuras, portadoras del principio de su propia perpetuación, se reproducen con la colaboración obligada de agentes sometidos a sus constricciones, cuanto la visión interaccionista o etnometodológica (o, en términos más amplios, marginalista), según la cual el mundo social es producto de los actos de construcción que en cada momento realizan los agentes, en una suerte de creación continua». 
dependería fundamentalmente de que estas «nuevas personas o grupos» integrados tuvieran acceso a manifestar legítimamente sus posiciones frente al Estado, influyendo activamente en el proceso de toma de decisión. Consecuentemente, la integración presupone la asunción del derecho de ciudadanía, pues la ciudadanía equivale a:

«La identidad que debe manifestar la persona cuando se relaciona con las instituciones estatales, y la única que las instituciones estatales reconocen como legalmente válida para relacionarse con las personas. (...) Siempre que se hable de ciudadanía deberá uno situarse en la confluencia de la relación entre la persona y el Estado» (Zapata-Barrero, 2001:48).

Caminamos así a la consideración de que, en un contexto de pluralismo social, la ciudadanía es también un espacio de mediación entre las personas y la unidad política básica (el Estado) (ZapataBarrero, 2001:49). Esta consideración nos enfrenta a la necesidad de comprender cómo la ciudadanía debe realizarse para garantizar la integración social a niveles políticos-estatales, sin abandonar los principios de libertad e igualdad que solidifican las bases de un Estado de derecho democrático y que encuentran su materialidad en la vida cotidiana de la gente común.

¿Cómo podemos pensar una ciudadanía plural sin que eso se convierta en un problema para la centralidad del Estado democrático? $\mathrm{O}$, en otras palabras, ¿cómo promover una noción política igualitaria (y, por ende, intrínsecamente unificadora y homogeneizadora), sin dejar de garantizar la libertad de una sociedad cada vez más pluralista y heterogénea? (Zapata-Barrero, 2001:05).

\section{LA TARJETA DE RESIDENCIA Y EL DERECHO A LA CIUDADANÍA DE LOS MIGRANTES EN ESPAÑA}

Si la centralidad de los Estados nacionales europeos se dio bajo la supresión de la pluralidad, entonces la intensificación de una «inesperada» migración también pone en cuestión los principios que dan por sentada esa misma idea de centralidad del Estado (Hobsbawn, 1997:183). La pluralidad social que se vive hoy día en los Estados europeos debería ser tomada como una oportunidad para reconocer y redimir el hecho de que en dichas democracias no «se 
ha tomado en serio la condición de la diferencia, que es constitutiva de nuestra propia realidad social, a la que aún queremos seguir viendo como homogénea» (De Lucas, 2001:64). En el caso de España, la dificultad de acceso a la ciudadanía/nacionalidad por parte de los migrantes reincide en la construcción de relaciones de exclusión que reproducen patrones del nacionalismo moderno, situación que se viene materializando a partir de dos mecanismos básicos:

\section{1) La dificultad de acceso a la concesión de la ciudadanía/nacionalidad ${ }^{14}$}

Se sobredimensionan y extienden los requisitos mínimos que permiten a la persona alcanzar el status de ciudadano. En muchos casos, este derecho viene supeditado a un criterio económico, estando limitado a aquellos que pueden probar su contribución económica (situación laboral estable) por un número prolongado de años. La visión instrumentalista (y utilitarista) del inmigrante como una mercancía (su mano-de-obra como producto circulante en el mercado nacional) es decididamente lo que da el tono de esa disociación entre su derecho al trabajo y su acceso a los derechos políticos (De Lucas, 2001:65).

Tomemos como ejemplo el caso de los inmigrantes latinoamericanos en España. Pasados dos años de su residencia en el país, esos inmigrantes pueden legítimamente acceder a la nacionalidad. El problema que enfrentan esos colectivos es el de conseguir el permiso de residencia que les facilite trabajar legalmente durante dos años en territorio nacional. Como este permiso de residencia está vinculado a la posesión de un contrato laboral estable, y como esa clase contratos corresponde invariablemente la excepción y no la regla del trabajo ofertado a los inmigrantes, los trabajadores latinoamericanos están expuestos a no poder cumplir con el tiempo de residencia legal que les concedería la nacionalidad.

14 La ciudadanía (referente a los derechos económicos, individuales, sociales y culturales, y que también concede el permiso de participación política en el sistema representativo) equivale en muchos países a la nacionalidad. Ese es el caso de España, donde el ejercicio del derecho político de voto solamente está disponible para los nacionales (Rubio y Moya, 2003:108). En consecuencia de ello, y para los objetivos aquí propuestos, nos limitaremos a entender la «ciudadanía integral» española como equivalente al derecho de nacionalidad. 
Generalmente, estos inmigrantes se involucran en trabajos ilegales - mal remunerados, sin seguridad médica, y sin condiciones laborales-sanitarias adecuadas - hasta que logran acceder a un contrato formal (De Lucas, 2001:72). Lógicamente, el recibimiento del $" \mathrm{NIF}{ }^{15}$ implicará dos años más de trabajo antes de que se pueda optar a la nacionalidad, cuyo trámite puede tardar otros dos o tres años adicionales. Cuando los inmigrantes llegan a acceder a la ciudadanización integral por el recibimiento de la nacionalidad, habrán pasado entre cinco a nueve años en España, trabajando y generando frutos económicos. Aún así, no hay que olvidar que nos estamos refiriendo específicamente al colectivo de latinoamericanos. El caso de los demás colectivos extra-comunitarios (no provenientes de la Unión Europea) es aún más grave, toda vez que el requisito para la nacionalización es de diez años de permanencia (con permiso de residencia) en territorio nacional.

La normativa de la Unión Europea - Directiva 2003/10/CEE, relativa al estatuto de los nacionales de terceros países residentes de larga duración - respalda esta tendencia de conceder derechos a los ciudadanos de países no miembros de la UE en la medida en que permanezcan por períodos considerables de tiempo en territorio europeo $^{16}$. El estatuto jurídico de la UE contempla una progresiva concesión de:

«Derechos y responsabilidades sobre una base de igualdad, pero diferenciado según el tiempo de estancia. Los residentes de larga duración amparados por el estatuto disfrutarán de igualdad de trato en diversos sectores: en el acceso a un empleo asalariado o autónomo; en la educación y formación profesional; así como en materia de protección y asistencia social. Gozarán también de mayor protección contra la expulsión» (Álvarez, 2006:54).

15 Sigla con la que se denomina la Tarjeta de Residencia dada a extranjeros en España.

16 La obligación de cumplir con una larga permanencia en los países como requisito para obtención de la ciudadanía/nacionalidad no viene generando un acceso igualitario a ciudadanía. Por el contrario, viene formando un grupo de ciudadanos que no terminan nunca de tener los mismos derechos que los considerados «autóctonos», constituyendo en esta medida una "ciudadanía de segunda clase» (Castle y Davidson, 2000:95). 
Este derecho fue extendido también a los ciudadanos de países terceros recibidos en la UE en la condición de «beneficiarios de protección internacional»(refugiados y exilados, mayormente) por la Directiva 2011/51 UE (11 mayo, 2011).

En el caso de los ciudadanos provenientes de países de la UE, denominados en España «migrantes comunitarios», la concesión de la Tarjeta de Residencia no está vinculada al contrato estable de trabajo, sino a la misma condición de ser ciudadano de algún país miembro. Estos ciudadanos reciben un derecho parcial a representación política, posibilitado por el art. 13.2 de la CE que fue reformado debido al tratado de Maastrich (7 febrero, 1992), pasando a otorgar «el derecho a ser elector y elegible en las elecciones municipales y en las elecciones al Parlamento Europeo (art. 8 B, 1 y 27) a todos los nacionales de los Estados miembros de la UE» (Rubio y Moya, 2003:109).

Aquí también opera un mecanismo de inclusión parcial, porque si bien es cierto que los «comunitarios» acceden a la residencia con mucha más facilidad, por otro lado también es correcto que esta condición no les permite obtener igualdad de condiciones respecto a los nacionales en lo que se refiere a los derechos políticos. Lo curioso es que se les otorga un derecho político ejercible aparentemente en un polo micro-nacional y en otro extra-nacional: el primero, en la esfera local inmediata (la posibilidad de participación en las elecciones municipales por ejemplo); el segundo, en la esfera supra-estatal (en las elecciones al Parlamento Europeo). La nacionalización para ciudadanos comunitarios en España también estaría condicionada a la larga permanencia, dado que el «comunitario» tiene que completar 5 años de estancia con Tarjeta de Residencia en el país antes de dar entrada al pedido de nacionalidad.

Pese a todas las dificultades vividas por los migrantes (comunitarios o extra-comunitarios) para permanecer en España con Tarjeta de Residencia y pese al periodo prolongado de tiempo requerido para la gestión del pedido de nacionalidad, el número de los que logran hacerlo ha crecido considerablemente en los últimos diez años. La nacionalización por residencia es la principal forma de nacionalización de los migrantes en el país (OPAM, 2012:2). Entre 1995 y 2011, España nacionalizó a un total de 749.563 personas ${ }^{17}$, entre ellas 114.599 solamente en 2011 (OPAM, 2012:2). El número

17 Se computan también los hijos de españoles nacidos en el extranjero (OPAM, 2012:4). 
de nacionalizaciones acumuladas entre 1995 y 2011, si se observa aisladamente, resulta impactante, pero su magnitud se redimensiona cuando lo comparamos con los totales registrados de población migrante con Tarjeta de Residencia.

Entre 2002 y 2011, el stock acumulado de migrantes con Tarjeta de Residente alcanzó 5.252.000 personas (OPAM, 2012:5). Con estos datos uno puede tener una dimensión más clara de que acceder a la nacionalización no está al alcance de la mayoría: la cifra de nacionalizaciones acumuladas entre 1995 y 2011 equivale a aproximadamente el 14,3\% del stock acumulado de migrantes con Tarjeta entre 2002 y 2012. Y sobre esto, habría que considerar que el número de migrantes con Tarjeta dista de la realidad total de los migrantes, ya que no computa aquellos sujetos que están indocumentados.

2) La concesión de ciudadanías parciales —desvinculación del derecho al trabajo y al consumo de los derechos políticos, estatales, cívicos.

«(...) la visión dominante acerca de la inmigración prima por una concepción instrumental (...). Esa visión instrumental viene exigida por la ficción de que la presencia del extranjero, del inmigrante (y con ello su estatus jurídico y político, lo que podríamos llamar el "contrato de extranjería” en relación con la ciudadanía), es provisional, parcial, superficial. (...) El inmigrante no puede aspirar al contrato de ciudadanía, sino a otro contrato, provisional, parcial, transitorio y evidentemente inferior». (De Lucas, 2001:65).

De Luca se refiere básicamente a la eternización del extranjero en la condición de «residente». El residente (y el derecho a la Tarjeta de Residente) imputa un status de pertenencia parcial, en la medida en que concede el derecho legítimo de trabajar en jornada integral, de ser asistido por el servicio sanitario, y de frecuentar los servicios públicos de educación, pero restringe el ejercicio de la representación política. Esa es una concesión que solamente cumple con las libertades negativas (la seguridad jurídica), impidiendo que los inmigrantes disfruten integralmente de los derechos sociales y políticos que conforman la condición de ciudadanía plena (Bauböck, 1994: 175; De Lucas, 2001:69). La denegación del derecho a voto provoca una pérdida de capacidad de presión política por parte de los migrantes, ya que los representantes políticos tenderán a no 
escuchar sus demandas, sabiendo que ellas no se canalizarían en una ventaja electoral clara (Castles y Miller, 2004). El residente no puede ser un ciudadano, puesto que se encuentra privado del derecho al diálogo legítimo con el Estado; lo mismo que Ramoneda ha denominado sarcásticamente «el ciudadano-NIF» (Ramoneda en De Lucas, 2001:71). Simultáneamente, el «ciudadano NIF» es obligado a cumplir con las disposiciones económicas que caben a todos los ciudadanos, pues debe trabajar con contrato formal para ser residente y contribuir con sus impuestos, además de afiliarse a la seguridad social. El «inmigrante-NIF» es un ciudadano que aporta económicamente a la nación sin tener derecho a voz política.

Es el art. 25 del Pacto Internacional de Derechos Civiles y Políticos (19 diciembre, 1966) el que establece en la UE que el derecho a «votar y ser elegido se restringe a los ciudadanos» (Rubio y Moya, 2003:109). Existen otras tres normativas de la UE destinadas a legislar sobre el tema. Las dos primeras, firmadas y ratificadas por España, establecen la inclusión de los derechos políticos a ciudadanos de «terceros países». Serían ellas: 1) el Convenio Europeo de Protección de los Derechos Humanos y Libertades públicas (4 noviembre, 1950); el Convenio del Consejo de Europa que publica el Estatuto de Trabajadores Migrantes (24 noviembre, 1977). La tercera normativa (art. 42, Convenio Internacional de Protección de Derechos de Trabajadores y sus Familiares),

«que España no ha firmado y que aún no ha entrado en vigor, dispone que los Estados facilitarán, de conformidad con su Derecho nacional, la consulta o la participación de los trabajadores migratorios y sus familiares en las decisiones relativas a la vida y la administración de las comunidades locales. (...) Aunque proclama la posibilidad del goce de tales derechos por parte del trabajador extranjero, deja a la absoluta discrecionalidad de cada Estado la determinación de su contenido y modo de ejercicio» (Castro y Moya, 2003:110).

La validez y aplicación de estas legislaciones sobre extranjería en España es objeto de disputa interpretativa. Freixe y Remontti (1998:107) consideran que el art. 13.1 CE ${ }^{18}$ debiera ser interpretado

18 Según el cual «los extranjeros gozarán en España de las libertades públicas que garantiza el presente Título en los términos que establezcan los tratados y la ley» (Freixe y Carbonell, 1998:107). 
siguiendo las exigencias del art. 10.2 CE. Éste último dispone que «las normas relativas a los derechos fundamentales y a las libertades que la Constitución reconoce se interpretarán de conformidad con la Declaración Universal de Derechos Humanos y los tratados $\mathrm{y}$ acuerdos internacionales sobre las mismas materias ratificados por España» (Idem, 108). Así, las declaraciones y acuerdos internacionales firmados tendrían peso constitucional, direccionando la interpretación de la carta magna y su aplicación. Esto lleva a que los autores afirmen que las directrices del Pacto Internacional de Derechos Civiles y Políticos ${ }^{19}$ debieran garantizar en España la consecución de derechos políticos a los extranjeros.

\section{CONSIDERACIONES FINALES: CAMINAR HACIA CONSENSOS DIALÓGICOS E INCLUSIÓN PLURALISTA}

La constatación de un modelo de obstrucción parcial, temporal o completa de la participación política de los migrantes nos enfrenta, una vez más, a la problemática sobre cómo hacer que la diversidad de opiniones sea efectivamente escuchada por el Estado democrático. Aquí corremos el riesgo de caer en un falso dilema: ¿El cambio de mentalidades debe partir del Estado hacia la gente o de la gente hacia el Estado? Decimos que es falso porque encierra una concepción dualista y estática del sistema democrático. En un régimen legitimado por la voluntad popular, el Estado no puede asumir la función de promover los cambios sociales «desde arriba» (Parekh, 2000). Al contrario, las adaptaciones de mentalidad que deben sufrir las estructuras estatales - tanto en sus instituciones, como en las acciones emprendidas- deben responder, en primera instancia, a una demanda que emana de la sociedad civil:

19 Pacto firmado y ratificado por España y que «obliga a los Estados signatarios a respetar y garantizar los derechos políticos que en él se reconocen a todos los individuos que se encuentren en su territorio y estén sujetos a su jurisdicción, sin distinción alguna de raza, color, sexo, idioma, religión, opinión política o de otra índole, origen nacional o social, posición económica, nacimiento o cualquier otra condición social»(Freixa y Remontti, 1998:109). 
«Sólo mediante la multiplicación de las prácticas, de las instituciones y de los discursos que modelan "individualidades democráticas" se puede contribuir a consolidar el consenso a cerca de las instituciones democráticas. Eso, evidentemente, supone que quienes se reconocen como ciudadanos democráticos valoran las modalidades de individualidad que esta sociedad les ofrece y que, de esta suerte, están dispuestos a defender las instituciones que son su condición misma de existencia. (...)Es preciso concebirla [la ciudadanía] como ejercicio de la democracia en las relaciones sociales, que son siempre individuales y específicas, lo que requiere una real participación en las prácticas sociales que tejen la trama tanto del Estado como de la sociedad civil». (Mouffe, 1999:21).

De acuerdo a lo expuesto, consideramos que el Estado español necesita repensar su concepto de ciudadanía si lo que quiere es solucionar esta distorsión y evitar la generación (desde las estructuras del Estado) de la desigual concentración de renta y de derechos (De Lucas, 2001:64). Habría que evitar que la división entre autóctonos y extranjeros termine por configurarse como una división entre los mejor y peor situados socialmente; los que viven los derechos democráticos y los que son privados de ellos. De igual manera, habría que romper los lazos culturales y psicológicos que impregnan el sentimiento de ciudadanía de un carácter nacional-racial, con la consiguiente racialización y etnificación de la desigualdad económica. Una ciudadanía que permita el derecho de expresión política a los nuevos miembros del Estado es fundamental para evitar un proceso que ya vemos instalarse claramente en la realidad española: la marginación estructural del migrante procesada a partir de sus condiciones jurídicas y que resulta tanto en un déficit de acceso a la educación (Diez, 2006), al ocio y consumo (Santamarina, 2005), a la sanidad, como a los usos del espacio público y a la vivienda (Colectivo IOÉ, 2004; Martínez Veiga, 1999).

Para que ese cambio de mentalidades sea posible, es preciso articular espacios dialógicos donde las personas encuentren la posibilidad de expresarse con la certeza de que sus diferencias serán escuchadas. Espacios societarios donde puedan, efectivamente, construirse las normas que regularán la vida cotidiana, ya que existen ámbitos de la vida societaria que no pueden ser legítimamente regulados por el Estado democrático (Parekh, 2000). Es en ellos donde hay que generar mecanismos que instauren un clima de convivencia, más allá de la mera coexistencia y tolerancia (Giménez, 
2005). La ausencia de esa posibilidad dialógica de convivencia podría derivar en una situación delicada, pues:

«En efecto, cuando no hay apuestas democráticas en torno a las cuales puedan cristalizar las identificaciones colectivas, su lugar es ocupado por otras formas de identificación de índole étnica, nacionalista o religiosa, y de esa suerte el oponente [el inmigrante versus el autóctono y viceversa] se define con base a tales criterios. En esas condiciones ya no se puede percibir como un adversario, sino que aparece como un enemigo que hay que destruir. Y eso es lo que una democracia pluralista tiene que evitar». (Mouffe, 1999:17).

Si la integración social depende tanto de la adaptación mutua entre sujetos culturalmente diferenciados como del reconocimiento y transformación de las instituciones del Estado, entonces esa integración, que a nivel social puede (potencialmente) acontecer horizontalmente entre las personas, necesita dar paso a una identidad política diferenciada (a una ciudadanía), para que sus impactos alcancen al Estado, permitiendo, de ese modo, el diálogo por un nuevo "consenso social». Un consenso que, sin embargo, no sería cristalizado como una forma objetiva o neutral, gozando constantemente del proceso pluralista de re-cuestionarse y re-actualizarse. En este consenso dialógico (Parekh, 2000:265) se hacen concesiones y compromisos que las partes involucradas pueden sentir como difíciles y dolorosos, debido a que encontrar una solución que permita conciliar el derecho de libertad de unos y otros no es sencillo y difícilmente se pueden aplicar las mismas recetas a todos los casos (Parekh, 2000).

En lo que coinciden buena parte de los analistas sobre este proceso, es en reconocer que la defensa de los derechos del individuo - punto articulador de la idea de democracia liberal - no es suficiente para salvaguardar el «derecho a la diferencia» en los Estados democráticos cada vez más pluralizados por los flujos humanos y económicos de la era de la globalización (Kymlicka, 1995:171). Esto porque los derechos del individuo fueron pensados en el contexto de sociedades (occidentales) específicas, contemplando solamente un tipo específico de subjetividad, marcadamente urbana, cosmopolita e individualista, donde la separación entre persona pública y persona privada determina la posibilidad de manifestar o no las adhesiones religiosas, corporales, de costumbre y morales. La dificultad de establecer una división clara entre público y privado en sociedades donde las culturas se multiplican, lleva a plantear la necesidad de dar vida a concepciones más 
interculturales del derecho individual; o de combinar el derecho individual con la defensa del «derecho de las minorías» (Kymlicka, 1995).

La pluralización cultural de los Estados europeos en las últimas décadas viene poniendo en evidencia la necesidad de generar instrumentos sociales a partir de los cuales las diferencias puedan ser dialogadas en la esfera pública. Esa misma pluralización viene provocando, al mismo tiempo, asimetrías entre el discurso democrático oficial de dichos Estados y su negativa práctica en: 1) permitir a inmigrantes, refugiados, exiliados y extranjeros en general, su acceso al status jurídico de ciudadanía; 2) el derecho de manifestarse grupalmente como "miembros de una comunidad política» (Mouffe, 1999:18) que hace uso de su fuerza laboral (Bauböck, 1994: 172-179). La libertad de mercado que acompañó el proceso de globalización internacional de la economía también resultó en el endurecimiento de las políticas de vigilancia de los flujos humanos y de concesión de derechos ciudadanos en toda la Unión Europea, dando paso a una ideología del cierre de fronteras: el «Fortress Europe» (Blum, Gozan y Haney, 2000:44).

La pluralidad manifiesta en Estados como el español, viene apareciendo en el debate público como un desafío al delicado equilibrio de la báscula de la democracia, siempre oscilando entre la centralidad política necesaria a cualquier Estado, y la libertad de manifestación de la diferencia. Estamos ante un momento político en que nos cabe un gran esfuerzo: re-inventar las instituciones democráticas, evitando su cristalización en normas que terminen por excluir antes de siquiera lograr plantear la inclusión.

Más allá del grado de esfuerzo que se necesite para llegar a formas consensuadas que integren a la pluralidad de gentes, debiéramos considerar que un consenso democrático nunca puede asumir los valores públicos operantes [operative public values] (Parekh, 2000:266) como si éstos fueron axiomáticos (Parekh, 2000:270-271). Con esto, evitaríamos fijar los valores de un determinado segmento social como objetivamente válidos para todos (Mouffe, 1999:12), evitando constituir el orden a partir de exclusiones originarias.

Consideramos así que tal como integración supone ciudadanía, supone también un consenso dialógico que acepte re-cuestionar los valores de la sociedad en nombre del respeto a la pluralidad y a la libertad. Pero, sobre todo, consideramos que integración, ciudadanía y consenso dialógico requieren repensar la noción de participación política en la esfera pública. De hecho, requiere relativizar la 
dicotomía entre público y privado, comprendiendo que las relaciones sociales constituidas en las esferas denominadas "privadas» por las ciencias políticas, desde Habermans (1982) a la fecha, son parte sine qua non del espacio público también. Estas prácticas ofrecen, a partir de la experiencia cotidiana de los sujetos, nuevas formas de constituir activamente la ciudadanía. Esto nos ayudaría a visualizar otros elementos de la participación ciudadana que devienen del micro-cosmos social. Al mismo tiempo, la atención a estos nuevos elementos permitirá, como han señalado algunas teóricas feministas (Korteweg, 2006; Yuval-Davies, 1997), constatar que existe una producción activa de ciudadanía desde «esferas privadas» movidas básicamente por mujeres migrantes y relacionadas a su importante participación en espacios dialógicos comunitarios a nivel local (ya sea escolares, familiares, comunitarios, asociativos o religiosos).

Asimismo, consideramos que las democracias actuales deben ser capaces de conciliar la defensa de los derechos inalienables del individuo con el principio de la libertad individual, sin escamotear la existencia de los conflictos, de los antagonismos y de la historicidad del consenso (Mouffe, 1999:13-14). Retomamos con esto otro elemento fundamental: la percepción de que el consenso en un régimen democrático no puede abstraerse del conflicto imaginando que la cohesión social resulte de o conlleve la uniformidad social.

El consenso y la cohesión social a los que nos referimos aquí no implican el aniquilamiento de las diferentes perspectivas, ni conducen al solapamiento de las ideas divergentes a favor del refuerzo de alguna corriente de pensamiento o visión del mundo. Consenso y cohesión comportan la posibilidad de que las diferencias sean compartidas, dialogadas, recíprocamente testeadas y contestadas, dando origen a un acuerdo en el que se decida colectivamente respetar una determinada norma. Esta norma estará abierta a la crítica y a la re-invención.

\section{REFERENCIAS BIBLIOGRÁFICAS}

Althusser, L. (1969). Ideología y Aparatos ideológicos del Estado. Disponible en: http:/www.ucm.es/info/eurotheo/e_books/althusser/.

Álvarez Rodriguez, A. (2006). La transposición de directivas de la UE sobre la inmigración. Las directivas de reagrupación familiar y de residentes de larga duración. Serie Documentos. Barcelona, CIDOB. 
Anderson, B. (2007). Comunidades inventadas. Reflexiones sobre el origen y difusión del nacionalismo. México DF, Fondo de Cultura Económico.

Appadurai, A. (2006). Fear of Small Numbers. An Essay on the Geography of Anger. Duham, Duke University Press.

Bloemradd, I.; Korteweg, A.; Yurdakul, G. (2008). «Citizenship and Immigration: Multiculturalism, Assimilation, and Challenges to the NationState». Annual Review of Sociology, 34:153-79.

Blum, J. A; Gowan, T.; Haney, L. (2000). «Global Forces: Introduction Part One». En: Gowan, T. and Riain, S. Ó., Berkeley (eds.). Global Etnography. Forces, Connections and Imaginnations in a Postmodern World. Los Angeles, University of California Press, pp. 43-47.

Boвbio, N. (1993). Igualdad y Libertad. Barcelona, Paidós.

Bourdieu, P. (2011). Las estrategias de la Reproducción Social. Buenos Aires, Siglo Veintiuno Editores.

Brubaker, R. (1992). Citizenship and Nationhood in France and Germany. Cambridge, Harvard University Press.

Butler, J. (2011). «Replantear el universal: la hegemonía y los límites del formalismo». En: Judith Butler, Ernesto Laclau y Slavou Zizek: Contingencia, hegemonía, universalidad: diálogos contemporáneos de la izquierda. Buenos Aires, Fondo de Cultura Económica, pp. 19-50.

CAsaús-Arzú, M. E. (2006). «La verdadera magnitud del racismo: ensayo para una definición y algunas consideraciones». Puntos de Vista: Cuadernos del OMCI, II (6), pp. 7-29.

Castles, S. y Davidson, A. (2000). Citizenship and Migration: Globalization and the policies of belonging. Hampshire, Macmillan Press.

Castles, S. y Miller, M. J. (2004). La era de la migración. Movimientos internacionales de población en el mundo moderno. México DF: UAZ/INM/ Fundación Colosio.

Colectivo IOÉ (2004). Inmigración y Vivienda en España. Madrid, Observatorio Permanente de las Migraciones/Secretaria de Estado de Inmigración y Emigración-Ministerio de Trabajo y Asuntos Sociales.

Constitución Española (1978). Versión digital. En: http://www.la-moncloa.es/ Espana/ElEstado/LeyFundamental/default.htm

De Lucas, J. (2001). «Hacia una ciudadanía inclusiva. Su extensión a los inmigrantes». Afers Internacional, 53, pp. 63-75.

Diez, J. (2006). Las dos caras de la Inmigración. Madrid: Observatorio Permanente de la Inmigración/ MTAS.

Durkheim, E. (1993). Las reglas del método sociológico. Madrid, Ediciones Morata.

Evens, T. M. S (2006). «Some Ontological Implications of Situational Analysis». En: Evens, T. M. S y Handelman, D. The Manchester School. Practice and Ethnographic Praxis in Anthropology. pp. 49-63.

Fabian, J. (2007). Memory against Culture. Arguments and Reminders. Durham y Londres, Duke University Press. 
Foucault, M. (2004) Vigiar e Punir: Nascimento da Prisão. Petrópoles, Vozes.

- (2006). Historia de la Sexualidad I. La voluntad del saber. Madrid, Siglo Veintiuno.

- (2007). «La gubernamentalidad». En: Giogi, G. y Rodriguez, F. (comps.). Ensayos sobre Biopolítica, excesos de vida. Barcelona, Paidós, pp.187-215.

GiménEZ, C. (1993). «¿Qué entendemos por integración de los inmigrantes? Una propuesta conceptualizada». Entreculturas - Caritas Española, 7, pp. 12-13.

- (2005). «Convivencia: Conceptualización y sugerencias para la praxis». Cuadernos Puntos de Vista del Observatorio de las Migraciones y de la Convivencia Intercultural de la Ciudad de Madrid, I(1), pp. 7-32.

Habermans, J. (1982). Historia y crítica de la opinión pública. La transformación estructural de la vida pública. Barcelona, Editorial Gustavo Gili.

Hastings, A. (2000). La construcción de las nacionalidades. Londres-Nueva York, University of Cambridge Press.

Hobsbawn, E. (1997). Naciones y Nacionalismos desde 1780. Barcelona, Crítica.

HoBSBAwn, E. y RANGER, T. (1984). «Introduction: Inventing traditions». Hobsbawn, E. y Ranger, T. (ed.) The invention of tradition. Londres-Nueva York, Cambridge University Press.

INE (1996-2011). Padrón municipal. Explotación Estadística. Cifras Oficiales de Población desde 1996. http://www.ine.es/jaxi/menu.do?type=pcaxis\&p ath $=\% 2 \mathrm{Ft} 20 \% 2 \mathrm{Fe} 245 \% 2 \mathrm{~F} \&$ file $=$ inebase $\& \mathrm{~L}=0$.

- (2011). Encuesta de condiciones de Vida: 2011 datos provisionales. Notas de prensa. http://www.ine.es/prensa/np680.pdf

Kazama, A (2011). "Local Citizenship and the realization of political rights of Japonese Brazilians: comparatives studies of Aichi and Yamanashi Prefectures of Japan». The 4th International Conference on Human Rights \& Human Development. Critical Connections: Human Rights, Human Development and Human Security, 18-19 August 2011.

Korteweg, A. C. (2006). «The construction of gendered citizenship at the welfare office: an ethnographic comparison of welfare-to-work workshops in the United States and the Netherlands». Social Politcs, 13(3):313-40.

Kymlicka, W. (1995). Multicultural Citizenship. Oxford-Nueva York, University of Oxford Press.

Martínez VeigA, U. (1999). Pobreza, segregación y exclusión espacial. La vivienda de los inmigrantes extranjeros en España. Barcelona, Icaria-Institu Català d'Antropologia.

Marshall, T. H. (1992). Ciudadanía y clase social. Madrid, Alianza Editorial.

Milkman, R. (2011). «Immigrant Workers, Precarious Work, and the US Labor Movement». Globalizations, 8(3): 361-372.

Mouffe, C. (1999). El retorno de lo político. Comunidad, ciudadanía, pluralismo, democracia radical. Barcelona, Buenos Aires y México, Paidós.

OPAM (2012). Evolución y características principales de los inmigrantes nacionalizados en España. Temas OPAM, 6: 1-12. 
Parekh, B. (2000). Rethinking Multiculturalism. Cultural Diversity and Political Theory. Houdmills, Basingstoke, Hampshire y Londres, Macmillan Press.

Rubio Castro, A. y Moya Escudero, M. (2003). «Nacionalidad y ciudadanía: una relación a debate». Anales de la Cátedra Francisco Suárez, 37: 105-153.

SANTAMARINA, C. (2005). Consumo y ocio de los migrantes latinoamericanos en España. Un acercamiento desde la perspectiva cualitativa. Madrid: Observatorio Permanente de la Inmigración/ MTAS.

Zapata-Barrero, R. (2001). Ciudadanía, democracia y pluralismo cultural: hacia un nuevo contrato social. Barcelona, Anthropos Editorial.

Yuval-Davis, N. (1997). «Women, Citizenship and Difference». Feminist Review, 57: 4-27. 